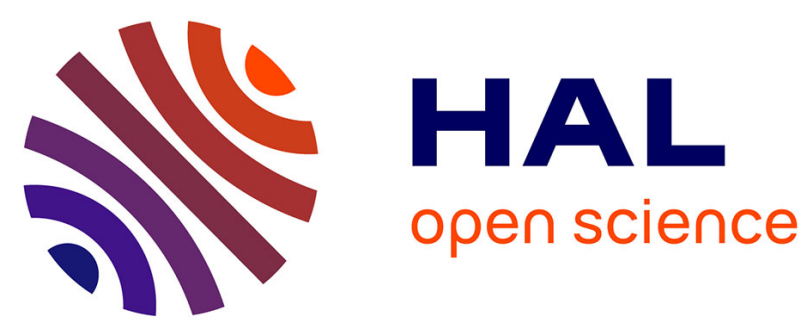

\title{
Structural Characterization of Intercalated C2Fx Compounds Using XAFS Polarization Dependencies
}

\author{
N. Bausk, S. Erenburg, N. Yudanov, L. Mazalov
}

\section{To cite this version:}

N. Bausk, S. Erenburg, N. Yudanov, L. Mazalov. Structural Characterization of Intercalated C2Fx Compounds Using XAFS Polarization Dependencies. Journal de Physique IV Proceedings, 1997, 7 (C2), pp.C2-1167-C2-1168. 10.1051/jp4:19972176 . jpa-00255242

HAL Id: jpa-00255242 https://hal.science/jpa-00255242

Submitted on 1 Jan 1997

HAL is a multi-disciplinary open access archive for the deposit and dissemination of scientific research documents, whether they are published or not. The documents may come from teaching and research institutions in France or abroad, or from public or private research centers.
L'archive ouverte pluridisciplinaire HAL, est destinée au dépôt et à la diffusion de documents scientifiques de niveau recherche, publiés ou non, émanant des établissements d'enseignement et de recherche français ou étrangers, des laboratoires publics ou privés. 


\title{
Structural Characterization of Intercalated $\mathrm{C}_{2} \mathrm{~F}_{x}$ Compounds Using XAFS Polarization Dependencies
}

\author{
N.V. Bausk, S.B. Erenburg, N.F. Yudanov and L.N. Mazalov \\ Institute of Inorganic Chemistry, Siberian Branch of the Russian Academy of Sciences, \\ Lavrentiev ave 3, Novosibirsk 630090, Russia
}

\begin{abstract}
Orientation dependencies of FeK, $\mathrm{BrK}$ EXAFS and XANES spectra have been measured for intercalated compounds of the composition $\mathrm{C}_{2} \mathrm{~F}_{x}$ *yA $\left(\mathrm{X} \approx 1, \mathrm{~A}=\mathrm{Br}_{2}, \mathrm{BrF}_{3}, \mathrm{FeBr}, \mathrm{Fe}(\mathrm{AA})_{3}, \mathrm{FeCl}_{3}\right.$ ) synthesized by diffusion from solutions. An approach has been developed which allows determination of the ranges of the orientation angles of $\mathrm{T}$-shaped $\mathrm{BrF}_{3}$ molecules from XANES spectra. The values of the orientation angles of $\mathrm{BrF}_{3}$ molecules were determined by simultaneously analyzing EXAFS and XANES data. It was found that heating leads to the formation in the intercalated compound of lens-like regions containing oriented $\mathrm{BrF}_{3}$ molecules. The orientation and geometry of $\mathrm{Br}_{2}$ molecules in the studied compounds were shown to be substantially different from those in graphite intercalation compounds. The intercalation was shown to lead to deformation of the $\mathrm{Fe}(\mathrm{AA})_{3}$ molecule while the $\mathrm{FeCl}_{3}$ molecules form dimers
\end{abstract}

\section{INTRODUCTION}

Graphite fluoride intercalated compounds can be synthesized using methods based on a diffusion from solutions [1]. These compounds are of interest first because the intercalated molecules retain their mobility in directions parallel to the $\mathrm{C}_{2} \mathrm{~F}_{\mathrm{x}}$ matrix layers and can be viewed upon as two-dimensional liquids. Second, it appears promising to study chemical reactions in spaces between the $\mathrm{C}_{2} \mathrm{~F}_{\mathrm{x}}$ matrix layers under conditions when the reacting molecules are oriented relative each other. Such reactions may be used for the synthesis of new nanocomposite materials on the basis of graphite fluoride. The matrix layers formed in the fluorination of graphite are partially covered by fluorine atoms and are not plane which suggests the presence of some orientation of intercalated molecules relative the layers. It is therefore important to establish the spatial structure and orientation of intercalated molecules in the $\mathrm{C}_{2} F_{x}$ matrix. XRD data allow determination only of the interlayer distances for filled and unfilled layers for different intercalants. NMR data indicated a Van-der-Waals character of the interaction between the intercalated molecules and the presence of some ordering. We have used in present work XAFS spectroscopy since its possibilities were demonstrated in studies of graphite intercalation compounds (GICs) [2-4].

\section{EXPERIMENT}

The following compounds synthesized by the diffusion procedure described in [5] have been studied : $1-\mathrm{C}_{2} \mathrm{~F}_{0.86} \cdot 0.13 \mathrm{Br}_{2} ; 2$ $\mathrm{C}_{2} \mathrm{~F}_{1,02} \mathrm{O} 0.11 \mathrm{BrF}_{3} ; 3-\mathrm{C}_{2} \mathrm{~F}_{1.02} 0.11 \mathrm{BrF}_{3} ; 4-\mathrm{C}_{2} \mathrm{~F}_{0.92} 0.078 \mathrm{FeBr}_{3} 0.021 \mathrm{CHCl}_{3} ; 5-\mathrm{C}_{2} \mathrm{~F}_{0.86} \cdot 0.011 \mathrm{Fe}(\mathrm{AA})_{3} \cdot 0.047 \mathrm{C}_{6} \mathrm{H}_{6}$ (where $\mathrm{AA}=$ acetilaceton); $6-\mathrm{C}_{2} \mathrm{~F}_{0.86} \cdot 0.037 \mathrm{FeCl}_{3} \cdot 0.06 \mathrm{CHCl}_{3}$. Sample 3 has been prepared by the Sample 2 heating for $20 \mathrm{~min}$ at $200^{\circ} \mathrm{C}$ in a nitrogen atmosphere. For these compounds XRD has allowed determination of interlayer distances. For Sample 2 only the presence of reflections characteristic of unfilled matrix were found. It was therefore assumed that in Sample 2 the $\mathrm{BrF}_{3}$ molecules are concentrated in defective lens-like regions. Textured samples with layers misorientation of about $\pm 4^{\circ}$ and a thickness allowing to avoid self-absorption effects were prepared from the synthesized compounds.

The polarization dependencies of FeK, BrK EXAFS and XANES spectra were measured at the VEPP-3 storage ring ( Institute of Nuclear Physics, Novosibirsk) in the fluorescence detection mode nsing a gas electroluminescent detector in a current mode. A channel-cut Si(III) single crystal was used as monochromator. The higher reflection orders of the monochromator were filtered with a flat Au-coated mirror. The flat textured samples were arranged so that the vector of the normal to the layers was in the horizontal plane and were rotated around the vertical axis.

\section{RESULTS AND DISCUSSION}

The angle between the axis of a diatomic molecule and the vector of the normal to the matrix layers, $\delta$, can be determined by measuring a $\sigma$-resonance intensity in XANES at two orientation angles [2]. In the present work intensities of XANES resonances were determined by subtracting arctan step function [2] from a normalized spectrum. As an illustration, in Fig.1 are 

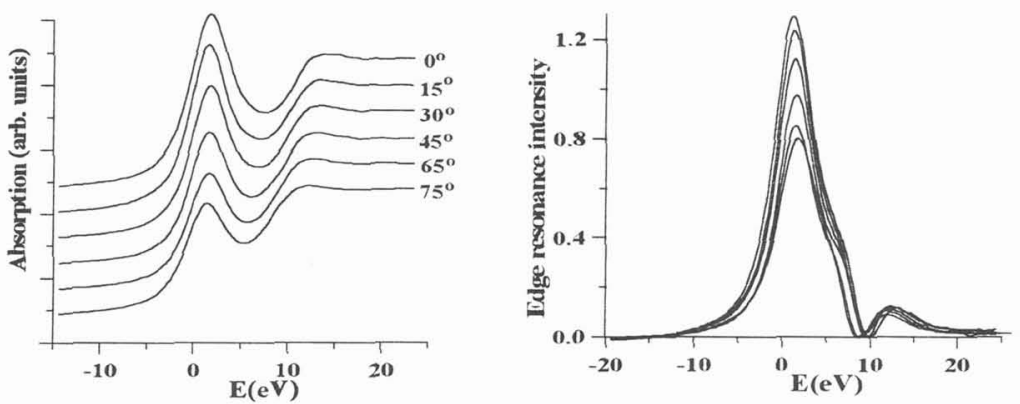

Fig.1. BrK XANES spectra measured on the Sample 1 at various angles between the $\mathrm{C}_{2} \mathrm{~F}_{\mathrm{x}}$ matrix layers and polarization vector and respective near-edge resonances.

shown BrK XANES spectra and the corresponding resonances for the Sample 1. The ratios of all possible pairs of intensities were averaged and a r.m.s. error was calculated resulting in $\delta=63^{\circ} \pm 1.5^{\circ}$. EXAFS data were processed using EXCURV92 program. The onientation angle $\delta$ calculated using angular dependence of effective coordination numbers of $\mathrm{Br}$ atoms obtained by fitting of Fourier-filtered was found to be equal to $64^{\circ} \pm 1.5^{\circ}$. The $\mathrm{Br}-\mathrm{Br}$ distance obtained coincides, within the error, with such distance for the $\mathrm{Br}_{2}$ molecule in the gas phase. The difference between the obtained values and those for $\mathrm{Br}_{2}$ in GICs [4] is not surprising since in our case the interaction with the matrix has a Van-der-Waals character.

For multiatomic molecules with equivalent bonds the averaged value $\left\langle\sin ^{2} \delta>\operatorname{can}\right.$ be calculated using XANES polarization dependencies [2]. For square planar and triangular molecules this relation allows determination of the angle between molecular planes and matrix layers only [5]. The $\mathrm{BrF}_{3}$ molecule has an almost ideal T-shape. Therefore two parameters are needed to describe its orientation. Normalizing and averaging of the XANES data for the Sample 2 has produced the following relationship between the orientation angles of $\mathrm{Br}-\mathrm{F}$ and $\mathrm{F}-\mathrm{Br}-\mathrm{F}$ bonds, $\delta_{1}$ and $\delta_{2}:\left(\sin ^{2} \delta_{1}+2 \sin ^{2} \delta_{2}\right) / 3=0.763 \pm 0.026$. This equation determines the relation between the orientation angles as well as the permissible ranges [5]: $\delta_{1}=27^{\circ} \div 82^{\circ}$ and $\delta_{2}=$ $52^{\circ} \div 90^{\circ}$ and the range of possible orientations of molecular planes $\gamma=27^{\circ} \div 53^{\circ}$. For Sample 3 the XANES data have produced the value of $\left\langle\sin ^{2} \delta\right\rangle$ equal to $0.761 \pm 0.043$ which is close to the value for Sample 2 . This means that the orientation angles of the $\mathrm{BrF}_{3}$ molecules in Samples 2 and 3 coincide. This allowed us to assume that in Sample 3 which was obtained by the heating of the Sample 2 the lens-like regions have a thickness of several molecular layers of $\mathrm{BrF}_{3}$ which ensures the molecular orientation at the expense of the contact of the boundary layers with the matrix.

The angular dependence of the effective coordination numbers of $\mathrm{Br}-\mathrm{F}$ can be used to determine the orientation angles since the $\mathrm{Br}-\mathrm{F}$ bond lengths in the $\mathrm{BrF}_{3}$ molecule in the gas phase differ by $0.08 \AA$. However, the accuracy of determination of the coordination numbers using EXAFS data does not exceed $\pm 10 \%$. Besides, in the fitting procedure these values correlated with the Debay-Waller factors. In the present work we employed the ratio of the effective coordination numbers to exclude the effect of these factors. The analysis of EXAFS data for Sample 2 in combination with XANES data has produced the following orientation angles: $\delta_{1}=58^{\circ} \pm 1.5^{\circ}, \delta_{2}=62^{\circ} \pm 1.5^{\circ}$ and $\gamma=45^{\circ} \pm 1.5^{\circ}$.

It was found that the FeK XANES spectra for sample 4 are independent of orientation which means either a magic angle or random orientation of the $\mathrm{FeBr}_{3}$ molecules. The fitting of the EXAFS data for sample 4 has produced the Fe-Br distance of $2.12 \pm 0.02 \AA$. The FeK XANES spectra of sample 5 were found to be substantially different from the spectra of the solid $\mathrm{Fe}(\mathrm{AA})_{3}$ and its solution in benzene indicating a distortion of the octahedral symmetry of the local environment of iron atoms. According to the EXAFS data the intercalation leaves unchanged only the first coordination sphere of the iron atoms. FeK XANES spectra of sample 6 do not change with the angle of orientation which indicates a high symmetry of the Fe environment in $\mathrm{FeCl}_{3}$. The fitting of Fourier-fitted data for the first clorine coordination sphere of Fe atoms has produced the following values: $R=2.19 \pm 0.01 \AA, \sigma^{2}=0.007 \pm 0.001 \AA^{2}, N=4.3 \pm 0.2$. The obtained data are in favor of a tetrahedral environment of the $\mathrm{Fe}$ atoms with chlorine atoms suggesting formation of $\mathrm{Fe}_{2} \mathrm{Cl}_{6}$ dimers as in the $\mathrm{FeCl}_{3}$ in the gas phase.

\section{Acknowledgments}

This work has been supported by RFBR Grant 03-94-09681.

\section{References}

[1] Yudanov N.F., Boguslavskiy E.G., Yakovlev I.I, Izvestiya Akademii Nauk, Ser. Khin. 2 (1988) 272-278.

[2] Niemann W., Ehrich J., Lochte K., Metz W., Behrens P., Conf.Proc.V25 (1990) 781-784.

[3] Ressler T, Hatje U., Lochte K., Metz W. Physica B 208\&209 (1995) 660-662.

[4] Feldman L., Elam W.T., Echrlich A.C., Phys. Rev. B 33 (1986) 7961-7969.

[5] Bausk N, Erenburg S., Mazalov N., Yudanov N., J. Structural Chemistry 36 (1995) 932-940. 